\section{Preliminary evidence that synanthropic flies contribute to the transmission of trachoma- causing Chlamydia trachomatis in Latin America}

\author{
Evidência preliminar que moscas sinantrópicas \\ contribuem à transmissão de Chlamydia \\ trachomatis causando tracoma na América Latina
}

\author{
1 Department of Biological \\ Sciences, University of \\ Warwick, Coventry, U.K. \\ 2 Instituto Evandro Chagas, \\ Belém, Brasil. \\ Correspondence \\ O. Courtenay \\ Ecology and Epidemiology \\ Group, Department \\ of Biological Sciences, \\ University of Warwick \\ Gibbet Hill Road, Coventry, \\ CV4 7AL, U.K. \\ orin.courtenay@warwick.ac.uk
}

\begin{abstract}
Synanthropic flies have been shown to be important mechanical vectors of Chlamydia trachomatis, which causes trachoma. However entomological studies have not been forthcoming in Latin America. This study assesses the relationship between household dipteran fly densities and active childhood trachoma in a village on Marajó Island, Pará state, Brazil. For 78 households, members were examined for signs of trachoma, relative abundance of potential trachoma vectors (Diptera, Chloropidae and Diptera, Muscidae) was quantified by trap counts, and additional measures of household hygiene associated with $\mathrm{C}$. trachomatis transmission were assessed. Active childhood trachoma prevalence was $24.1 \%$ (45/187), present in $46.2 \%$ of sampled households with evidence of case clustering. Childhood prevalence was positively associated with increased fly densities, whereas indirect measures of sanitary conditions (latrine ownership and perceived importance of flies) showed a protective effect. This study indicates that $\mathrm{C}$. trachomatis can be transmitted by synanthropic flies in this region of Latin America.
\end{abstract}

Trachoma; Chlamydia trachomatis; Disease Vectors
Lucy A. Reilly 1

Joana Favacho 2

Lourdes M. Garcez 2

Orin Courtenay 1

\section{Introduction}

Successful reductions in trachoma caused by Chlamydia trachomatis have recently been achieved in the Gambia by reducing the density of the filth fly Musca sorbens (Wiedemann), which constitutes an important arthropod vector along with the house fly Musca domestica in Africa 1,2,3, and the bush fly Musca vetustissima (Walker) in Australia 4.

In hyperendemic regions in Latin America, where childhood case prevalences are comparable to those in Africa and Asia 5,6, few epidemiological studies have been conducted, and to our knowledge none have investigated the potential role of synanthropic eye-seeking flies in Chlamydia transmission (M. sorbens does not occur in Latin America). In addition to Musca spp., eyegnats (Hippelates spp. and Liohippelates spp.) are likely to constitute an important vector group since like $M$. sorbens they swarm around eyes and bodily secretions 7 and can transmit Brazilian purpuric fever, for which the initial symptom is an acute conjunctivitis ${ }^{8}$.

This study aims (i) to quantify the relative abundance (measured by trap counts) of eyegnat and muscid flies in and around households in a trachoma endemic region in the Brazilian Amazon, and (ii) to evaluate fly density and anthroponotic features as significant risk factors of childhood trachoma. 


\section{Materials and methods}

\section{Study community}

The study was carried out between March and April 2004 on Marajó Island, located in the Amazon estuary in Pará State, Brazil. Data were collected from 78 contiguous houses in the secluded eastern section of the village of Umarizal (48³9'50"W, 053'50"S), where the household selection criterion was the full-time residency of at least one child $\leq 15$ years of age. The sample represented $90 \%$ of the houses in this section of the village and approximately $1 / 3$ of the total houses in the village. There were no apparent differences between sections of the village. The study population was defined as adults ( $\geq 16$ years), schoolaged children (6-15 years), and pre-school-aged children $(\leq 5$ years).

\section{Clinical survey and diagnosis}

Household members who were present at either one of two house-to-house visits and schoolaged children present at school visits were clinically assessed for signs of trachoma by examination of the conjunctiva of both eyes by a trained observer using a binocular loupe. Cases (defined as at least one infected eye) were scored following the World Health Organization's (WHO) simplified clinical grading scheme, which includes active infection (trachomatous inflammation-follicular and trachomatous inflammation-intense) and/or subsequent complications arising from repeated infection (trachomatous scarring, trachomatous trichiasis, and corneal opacity) 9 .

\section{Fly density}

Relative fly abundance was measured in each of the 78 study houses by hanging 2-3 yellow sticky fly traps (Pest Control Direct, Hailsham, Sussex, UK): one under the eaves at the entrance to the house, one in the kitchen, and one above the latrine (if present) for a recorded period of 6-12 days. Diptera on the fly papers were counted (disregarding insect parts) and classified into the taxonomic families (i) Muscidae or Fanniidae (e.g. house fly, stable fly, latrine fly - here termed Muscidae for simplicity); and (ii) Chloropidae (including eye-gnats: Hippelates spp. and Liohippelates spp.) using the keys of Smith 10 and Paganelli \& Sabrosky 7. All other Diptera were discarded. Public health disease vector control (insecticide spraying) had not been conducted for at least five years prior to the study.

\section{Additional risk factors for transmission}

The female head of each household was questioned about the frequency of face and hand washing by children (number of times per day), towel usage (ratio of the number of towels in use to the number of household members), the numbers of animals per household (dogs, chickens, ducks, pigs, and water buffalo), and the use of fly controls (yes/no). The household respondent was also asked to rank seven common pest insects (tick, flea, cockroach, housefly, mosquito, eyegnat, and sandfly), presented as picture cards, into increasing order of deemed importance as pests from 1 (least important) to 7 (most important). In addition to the questionnaire, the authors made observations regarding the presence or absence of a latrine and the severity of household litter accumulation in the area immediately surrounding the house ( 1 - low to 3 - high).

\section{Statistical analysis}

Statistical associations between household childhood ( $\leq 15$ years old) trachoma prevalence and relative fly abundance, and household trachoma status (presence/absence) and relative fly abundance were examined. Childhood trachoma prevalence is used here due to the probable role of children as a reservoir of active trachoma 11. Six households were excluded from these analyses due to lack of complete childhood examination records (i.e. $n=72$ ). Fly density explanatory variables included total fly counts of the defined groups stratified by trap location, in addition to fly count categorized by $\log (\mathrm{x}+1)$ transformation to test for trends in childhood prevalence with increasing $\log (\mathrm{x}+1)$ incremental fly exposure.

Variables or factors that were significantly associated with trachoma prevalence in univariate analysis (at the $10 \%$ level so as not to overlook any explanatory variables that may attain conventional significance in multivariate analysis) were entered into a multivariate model to explain the variation in trachoma outcome. Data were analyzed by univariate and backward stepwise multivariate logistic regression using Stata software, version 8 (Stata Corp., College Station, USA). In all analyses involving fly counts, number of trapping days was forced into the statistical models.

\section{Spatial analysis}

To test for geographical clustering of case houses, house locations were mapped in GIS (MapInfo version 6.0, MapInfo Corp., New York, USA) and buffer zones of $200 \mathrm{~m}$ radius created around each 
house. The numbers of trachoma positive and negative houses within each buffer zone were summed over all houses and statistically compared by chi-square. A $200 \mathrm{~m}$ radius was the minimum buffer size within which all houses had at least one neighbouring house (range: 1-13 neighbouring houses), thereby maximizing replicates.

\section{Ethics}

The work was conducted in full accordance with ethical principles and within the remit of the $\mathrm{Na}$ tional Trachoma Survey authorized by the Brazilian Ministry of Health 12 . Informed written consent was obtained from all study participants, or by proxy, prior to the study. Clinical and subclinical cases identified during this study were provided with $1 \%$ topical tetracycline or $20 \mathrm{mg} / \mathrm{kg}$ single dose oral azithromycin by trained staff from the Instituto Evandro Chagas (Belém, Brazil). To our knowledge, the community received no interventions or antibiotic treatment against trachoma prior to this study.

\section{Results}

\section{Trachoma prevalence}

A total 367 (85.8\%) of 428 people living in the 78 houses were clinically examined, including 180 (82.2\%) adults and 187 (89.5\%) children (0-15 yrs). All-age prevalence of trachoma was 15.8\% (58/367); childhood prevalence was $24.1 \%$ (45/187). All of the observed cases were trachomatous inflammation-follicular, except one case of trachomatous inflammation-intense with corneal opacity in a 13-year-old girl. There were no gender differences in age-specific trachoma prevalences.

\section{Relative fly abundance}

A total of 5,913 Muscidae and Chloropidae were caught in 1,554 trapping days by 193 sticky traps; an average of 3.9 flies caught per trap per day. The quantities of the two classification groups caught in the three trapping locations are shown in Table 1. The median number of these potential vectors caught per household was 43 (95\%CI: 31.4-55), with considerable aggregation between houses (Figure 1). Median numbers of flies caught per house in each taxonomic group were 3 (95\%CI: 2-4) Muscidae and 40 (95\%CI: 24.9-52.6) Chloropidae. Predominant capture sites were the kitchen for Chloropidae and outdoors for Muscidae (Table 1). Muscidae and/or Chloropidae were captured in 76 of the 78 houses, and $\geq 100$ Chloropidae specimens were trapped at $18 \%(14 / 78)$ of the households. Fiftyone Chloropidae collected from 5 sample dogs in 5 households were all confirmed as Hippelates spp. or Liohippelates spp.

\section{Association between household trachoma and fly density}

Household childhood trachoma prevalence was positively associated with total kitchen Chloropidae $(\mathrm{b}=0.003, \mathrm{z}=1.86, \mathrm{P}=0.063$ ) and total household Muscidae $(\mathrm{b}=0.004, \mathrm{z}=2.10, \mathrm{P}=$ $0.036)$. There was a positive trend in weighted mean childhood trachoma prevalence with an incremental increase in log transformed number of Chloropidae $(\mathrm{b}=0.737, \mathrm{z}=2.13, \mathrm{P}=0.033$ ) (Figure 2) but not with an increase in log transformed number of Muscidae $(b=0.272, z=0.71$, NS). In contrast, the probability of a household being trachoma positive (i.e. having $\geq 1$ case) was not related to any of the fly density measures tested.

Total catches and percentages of flies captured by sticky traps set in three domestic trapping locations in 78 houses, with the numbers and percentages of houses where each taxonomic group was captured.

\begin{tabular}{|c|c|c|c|c|c|c|c|c|c|}
\hline & \multicolumn{2}{|c|}{ Kitchen } & \multicolumn{2}{|c|}{ Outdoors } & \multicolumn{2}{|c|}{ Latrine } & \multirow[t]{2}{*}{ Total (100\%) } & \multicolumn{2}{|c|}{ Houses where captured } \\
\hline & $\mathrm{n}$ & $\%$ & n & $\%$ & $\mathrm{n}$ & $\%$ & & $n$ & $\%$ \\
\hline Muscidae & 91 & 27 & 150 & 45 & 93 & 28 & 334 & 63 & 81 \\
\hline Chloropidae & 3,775 & 68 & 909 & 16 & 895 & 16 & 5,579 & 76 & 97 \\
\hline Total & 3,866 & 65 & 1,059 & 18 & 988 & 17 & 5,913 & 76 & 97 \\
\hline Trapping days (n) & \multicolumn{2}{|c|}{653} & \multicolumn{2}{|c|}{425} & \multicolumn{2}{|c|}{476} & 1,554 & & \\
\hline
\end{tabular}


Figure 1

Frequency distribution of the total number of Muscidae and Chloropidae captured on sticky traps per household.

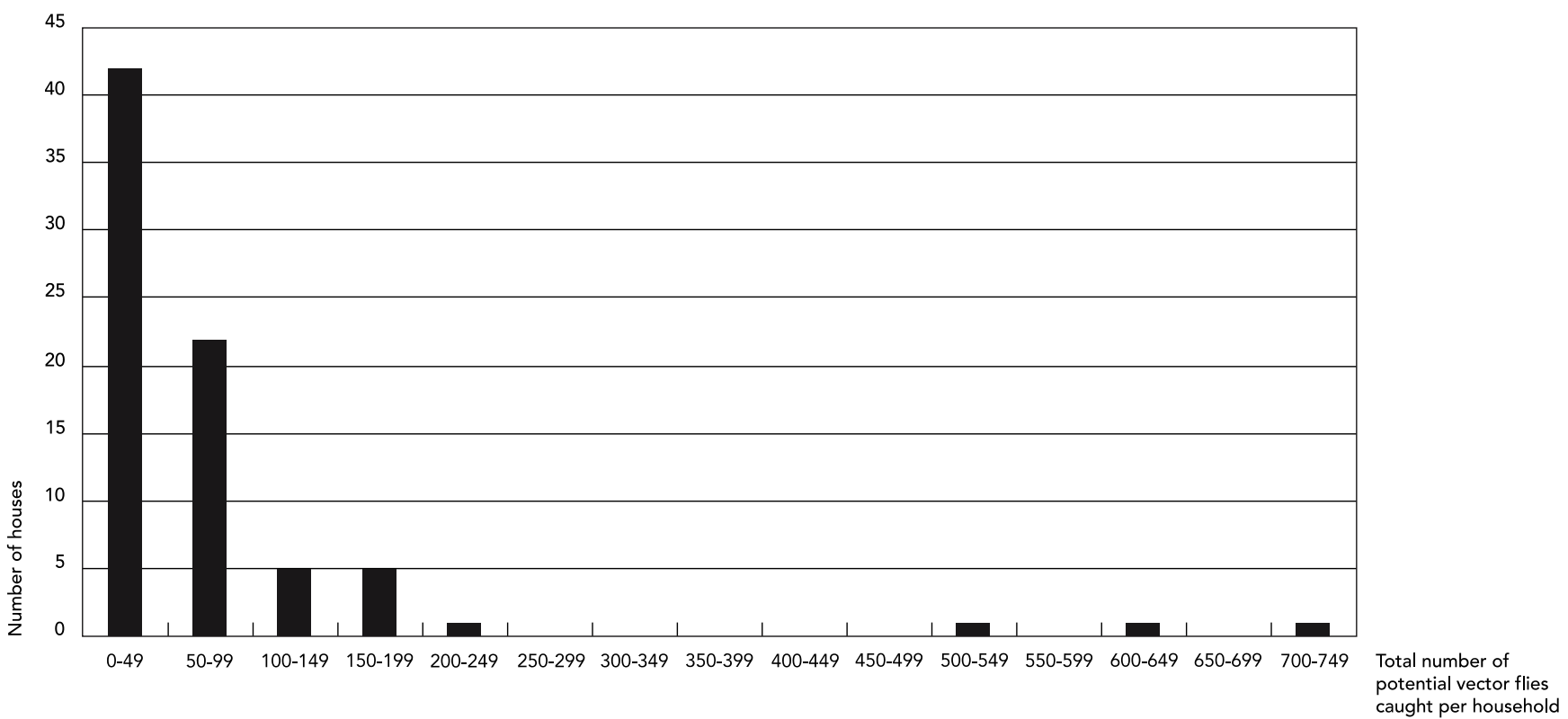

Figure 2

Weighted mean childhood active trachoma prevalence stratified by relative Chloropidae abundance. Error bars represent $95 \%$ confidence intervals. Shown sample sizes represent numbers of children examined.

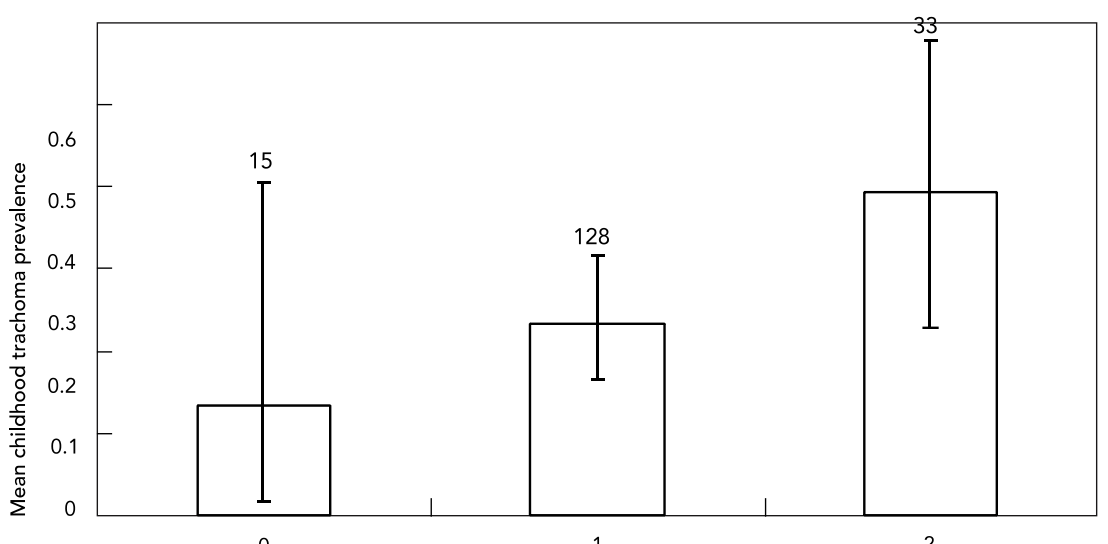

0

Log (Chloropidae count+1) 
Additional risk factors for

household trachoma

Clinical trachoma (all grades) was present in $50 \%(36 / 72)$ of the sampled households with complete clinical data; childhood prevalence reached $\geq 50 \%$ in 24 (66.7\%) of these households. Case clustering within houses was evident: $81 \%$ $(47 / 58)$ of the total cases were located in only $34.7 \%(25 / 72)$ of the households. The mean number of school-aged children in trachoma positive households was 2.11 (range 0-4) compared to 1.5 (range 0-4) in negative households. The probability of a household containing $\geq 1$ trachoma case increased with the numbers of school-aged children $(\mathrm{b}=0.404, \mathrm{z}=2.03, \mathrm{P}=$ 0.043 ), but was independent of the numbers of pre-school age children $(b=-0.343, z=1.16$, NS). Spatial clustering of trachoma positive houses was indicated by a greater proportion of infected households within a $200 \mathrm{~m}$ radius of trachoma positive houses (0.54 of 222) compared to trachoma negative houses (0.34 of 258) $\left(\chi^{2}=10.05\right.$, $\mathrm{P}=0.002)$. There was no associated spatial clustering of the fly groups.

None of the variables that might contribute to direct transmission risk (face washing and towel use) were associated with increased childhood trachoma prevalence, whereas a number of potential indirect measures of hygiene were. Childhood trachoma prevalence increased with the number of dogs owned $(b=0.188, z=1.98$, $\mathrm{P}=0.047$ ) and decreased with latrine ownership $(\mathrm{b}=-0.802, \mathrm{z}=2.06, \mathrm{P}=0.039)$ and the perceived importance of flies as pests $(b=-0.116, z=1.79$, $P=0.074$ ). Dog ownership ( $\geq 1 \mathrm{dog}$ ) was a significant risk factor for living in a trachoma positive vs. negative house $(\mathrm{OR}=2.68, \mathrm{z}=1.94, \mathrm{P}=0.053)$. The number of Chloropidae trapped in kitchens was negatively associated with the use of household fly control measures $(b=-0.964, z=2.76$, $\mathrm{P}=0.006$ ), whereas the numbers of Chloropidae captured outside houses was not $(b=0.502, \mathrm{z}=$ 1.73 , NS). Fly control measures had no effect on inside or outside Muscidae trap counts.

Finally, the multivariate model of household trachoma prevalence, adjusted for the significant variables from the univariate analyses, above, indicated that increased household Muscidae density $(\mathrm{b}=0.08, \mathrm{z}=1.91, \mathrm{P}=0.056)$ and number of dogs owned ( $b=0.20, z=1.96, P=0.050$ ) were significant risk factors for childhood trachoma, whereas latrine ownership $(\mathrm{b}=-1.08, \mathrm{z}=2.25, \mathrm{P}=$ 0.024) was protective.

\section{Discussion}

This study revealed positive associations between active trachoma prevalence in children and the densities of Muscidae and Chloropidae, which are both likely mechanical vectors of C. trachomatis. Previous studies in Africa and Australia have indicated the significant vectorial role of members of the Muscidae (M. sorbens, M. domestica and M. vetustissima) 1,2,3,13, and outdoor space spraying with deltamethrin to depopulate the filth fly ( $M$. sorbens) was recently shown to reduce trachoma incidence by $56-75 \%$ in The Gambia 1,2. No previous studies had been conducted to assess potential vectors in Latin America. However, eye gnats are serious pests to humans and animals in the southern half of North America (particularly Hippelates collusor in southern California), where they are thought to mechanically transmit conjunctivitis, yaws, and bovine mastitis 8,14 , and have been implicated as vectors initiating epidemic bacterial conjunctivitis 14 . In southern Brazil, Haemophilus aegyptius, the causative agent of acute conjunctivitis, has been isolated from eye gnats collected from around the eyes of children 8 .

Our data from Umarizal show that the highest numbers of eye gnats were collected on fly traps inside houses (68\%) compared to outdoors (16\%), with > 100 specimens trapped in $18 \%$ of all households. These flies were observed to concentrate around secretions and the scrotum of dogs, which appeared to facilitate fly entry into houses. The ownership of one or more dogs was a risk factor for childhood trachoma, though neither Muscidae nor Chloropidae densities varied with dog number. The predominance of Chloropidae in kitchens was also likely due to their attraction to stored fruit, vegetables, and meats that are favoured oviposition sites (the larvae feed on decaying organic matter). We did not observe flies collecting around the eyes of children in great abundance. However the authors noted that during periods of lower precipitation than the study period, eye gnats swarm and are highly attracted to bodily sweat. Indeed, the observed fly abundance during the study period was generally low for this region, the likely result of heavy rains at the time of the study (March to April); fly densities increase at the onset of the rainy season in January-February.

Trachoma prevalence was highest in Umarizal children, as opposed to adults, consistent with supporting evidence elsewhere 11,15 that children are the main reservoir (source) of C. trachomatis. However, we found no obvious risk of active disease associated with shared towel use or hand washing frequency despite the dem- 
onstrated role of shared fomites in hand to eye transmission 15,16. Perceived pest status of flies, use of fly controls, and latrine ownership - each inversely related to trachoma prevalence and/or household fly counts - appeared to be better surrogates of hygiene awareness. This finding is consistent with literature that commonly attributes increased trachoma risk to poor environmental sanitation 16 .

The possibility that well designed interventions to reduce indoor fly densities could reduce trachoma transmission in our study region is indicated by the observed inverse relationships between the casual use of indoor fly controls and both trachoma prevalence and the density of Chloropidae inside houses. Fly control measures adopted by Umarizal residents include cleaning household surfaces with soapy water and spirit alcohol, and indoor spraying with locally purchased insecticide (Baygon active ingredients: propoxur $0.75 \%$, cyfluthrin $0.025 \%$ ). As expected, fly counts outside houses were not affected by these fly control measures in this study.

\section{Resumo}

Insetos sinantrópicos são importantes vetores mecânicos de Chlamydia trachomatis, causadora de tracoma, contudo, estudos entomológicos não são freqüentes na América Latina. Esse estudo determina a relação entre densidade de dípteros domésticos e tracoma ativo na infância em uma vila na Ilha do Marajó, Estado do Pará, Brasil. Moradores de 78 residências foram examinados para sinais de tracoma e a relativa abundância de potenciais vetores de tracoma (Diptera, Chloropidae e Diptera, Muscidae) foi quantificada junto com medidas adicionais de higiene doméstica associada com a transmissão de C. trachomatis. A prevalência de tracoma ativo na infância foi $24,1 \%$ (45/187), presente em 46,3\% das residências amostradas com evidência de aglomeração de casos. A prevalência na infância foi positivamente associada com o aumento das densidades de insetos, enquanto medidas indiretas de condições sanitárias (possuir latrina e perceber a importância dos insetos) foram protetoras. Esse estudo indica que C. trachomatis pode ser transmitida por insetos sinantrópicos nessa região da América Latina.

Tracoma; Chlamydia trachomatis; Vetores de Doenças
Certainly not all species of Muscidae or Chloropidae are vectors of $C$. trachomatis. The strength of the observed statistical associations in this study may well reflect a lack of resolution resulting from our identification of Muscidae or Chloropidae to family, not genera of species, due to limited field resources. Fly densities were estimated using sticky traps because they are less selective and less laborious than other trapping methods. Although we might expect some sampling bias due to differential trapping efficiency between taxa, this is unlikely to be the case between households or between trap locations.

In sum, this is the first study to our knowledge to investigate the potential role of synanthropic arthropod vectors in transmission of ocular trachoma in Latin America. Unequivocal evidence of their epidemiological significance relative to direct modes of transmission will require controlled intervention studies directed against fly vectors. This will allow appropriate planning and execution of the "environmental improvements" component of the SAFE strategy, by which the WHO proposes to eliminate blinding trachoma by the year 202017 .

\section{Contributors}

L. A. Reilly directed collection of field data, performed statistical analyses, and collaborated in manuscript preparation. J. Favacho carried out all aspects of field data collection and trachoma clinical examinations. L. M. Garcez initiated the project and provided institutional collaboration. O. Courtenay helped supervise data collection and statistical analysis, and collaborated in manuscript preparation.

\section{Acknowledgements}

We are grateful to Norma Helem Medina, Maria de Fátima Lopes, and José Alfredo Guimarães, responsible for the project Inquérito Nacional de Tracoma. For help provided with fieldwork, we thank Patrick Gomes, Paolo Bahia, and Jose Maria. The work was supported by the University of Warwick Research Development Fund. 


\section{References}

1. Emerson PM, Lindsay SW, Walraven GEL, Faal HB, Bogh C, Lowe K, et al. Effect of fly control on trachoma and diarrhoea. Lancet 1999; 353:1401-3.

2. Emerson PM, Lindsay SW, Alexander N, Bah M, Dibba SM, Faal HB, et al. Role of flies and provision of latrines in trachoma control: cluster-randomised control trial. Lancet 2004; 363:1093-8.

3. Miller K, Pakpour N, Yi E, Melese M, Alemayehu W, Bird M, et al. Pesky trachoma suspect finally caught. Br J Ophthalmol 2004; 88:750-1.

4. Da Cruz L, Dadour IR, McAllister IL, Jackson A, Isaacs T. Seasonal variation in trachoma and bush flies in north-western Australian Aboriginal communities. Clin Experiment Ophthalmol 2002; 30:80-3.

5. Alves APX, Medina NH, Cruz AAV. Trachoma and ethnic diversity in the Upper Rio Negro Basin of Amazonas State, Brazil. Ophthal Epidemiol 2002; 9:29-34.

6. Reis ACPP, Chaves C, Cohen JM, Belfort F, Oliveira NP, Belfort Jr. R. Trachoma and corneal diseases among indians of the Alto Rio Negro, Amazonas, Brazil. Arq Bras Oftalmol 2002; 65:79-81.

7. Paganelli CH, Sabrosky CW. Hippelates flies (Diptera: Chloropidae) possibly associated with Brazilian purpuric fever. Proc Entomol Soc Wash 1993; 95:165-74.
8. Tondella MLC, Paganelli CH, Bortolotto IM, Takano OA, Irino K, Brandileone MCC, et al. Isolamento de Haemophiliis aegyptius associado à febre purpúrica brasileira, de cloropídeos (Diptera) dos gêneros Hippelates e Liohippelates. Rev Inst Med Trop São Paulo 1994; 36:105-9.

9. Thylefors B, Dawson CR, Jones BR, West SK, Taylor HR. A simple system for the assessment of trachoma and its complications. Bull World Health Organ 1987; 52:279-82.

10. Smith KGV, editor. Insects and other arthropods of medical importance. London: British Museum (Natural History); 1973.

11. West SK, Munoz B, Turner VM, Mmbaga BBO, Taylor HR. The epidemiology of trachoma in central Tanzania. Int J Epidemiol 1991; 20:1088-92.

12. Ministério da Saúde. Manual de controle do tracoma. Brasília: Fundação Nacional de Saúde; 2001.

13. Forsey T, Darougar S. Transmission of chlamydiae by the housefly. Br J Ophthalmol 1981; 65:147-50.

14. Day JF, Sjogren RD. Vector control by removal trapping. Am J Trop Med Hyg 1994; 50:126-33.

15. Schémann JF, Sacko D, Malvy D, Momo G, Traore $\mathrm{L}$, Bore O, et al. Risk factors for trachoma in Mali. Int J Epidemiol 2002; 31:194-201.

16. Prüss A, Mariotti SP. Preventing trachoma through environmental sanitation: a review of the evidence base. Bull World Health Organ 2000; 78:258-66.

17. World Health Organization. WHA51.11 Global elimination of blinding trachoma. Geneva: World Health Organization; 1998.

Submitted on 16/Mar/2006

Final version resubmitted on 18/Dec/2006

Approved on 12/Jan/2007 